\title{
The Role Of Valwes In Forming The Identity of Migrants ${ }^{1}$
}

\section{El papel de Valwes en la formación de la identidad de los migrantes}

\author{
Aliyeva Kamila \\ Doctor of Psychology, Professor, Baku, Azerbaijan \\ https://orcid.org / 0000-0003-4850-9400 \\ Jabbarov Rashid \\ Doctor of Psychology, Associate Professor Baku, Azerbaijan \\ https://orcid.org/0000-0002-0623-2772 \\ Irana Mammadli \\ Doctor of Philosophy in Psychology, Assistant Professor Baku, Azerbaijan \\ https://orcid.org/0000-0001-7990-6064

\section{Aliyeva Turana} \\ Doctor of Philosophy in Psychology, Assistant Professor Baku, Azerbaijan \\ https://orcid.org/0000-0003-3301-3599
}

Received 09-08-20 Revised 10-10-20

Accepted 20-12-21 On line 03-17-21

*Correspondencia

Email: bdu_sepp@mail.ru

(c) Universidad San Ignacio de Loyola, Vicerrectorado de Investigación, 2021.

\footnotetext{
${ }^{1}$ This work was supported by the Science Development Foundation under the President of the Republic of Azerbaijan- Grant .№ EIF / MQM / Science-Education-1-2016-1 (26) -71 / 08/5-M-05
} 


\section{Summary}

On the leading role of values for the development of identity and ensuring the effective adaptation of migrants to the new ethnocultural environment, during the research process, we set the task to identify the values of migrants living in Azerbaijan. At the same time, such factors as the length of residence in the country and the age of the respondents were taken into account. The study involved 235 migrants, of whom 98 are Koreans and 137 Turks, who have been living in Azerbaijan for at least five years, aged 18-40. There are 55 women among Koreans, 43 men, 87 men and 50 women among Turks. The results of our study showed that the lower the level of national identity, the greater the opportunity for migrants to choose a marginal adaptation strategy. This behavior strategy leads to dissatisfaction, social and psychological safety of the migrant. Having lost the values of their culture, the migrant loses an adequate standard "image of the world", which underlies the adaptation of the individual to the social environment. This means that the individual lacks values, patterns of adequate behavior, he has lost the significance of his culture, and therefore cannot adequately assess and accept the values of the host culture. Research has shown that a high level of indicators on such scales as the scale of interactivity (19\%) and the scale of adaptation (18\%) indicates that respondents feel confident enough in the new environment, are open to cooperation and are focused on self-realization, which gives them a sense of social and physical security. This situation, naturally, lowers the indicator on the scale of depression, which indicates the absence of serious emotional problems.

Key Words: values, identity, effective adaptation, , national identity ,culture

\section{Resumen}

Sobre el papel protagónico de los valores para el desarrollo de la identidad y garantizar la adaptación efectiva de los migrantes al nuevo entorno etnocultural, durante el proceso de investigación, nos propusimos la tarea de identificar los valores de los migrantes que viven en Azerbaiyán. Al mismo tiempo, se tuvieron en cuenta factores como el tiempo de residencia en el país y la edad de los encuestados. En el estudio participaron 235 inmigrantes, de los cuales 98 son coreanos y 137 turcos, que han estado viviendo en Azerbaiyán durante al menos cinco años, de entre 18 y 40 años. Hay 55 mujeres entre los coreanos, 43 hombres, 87 hombres y 50 mujeres entre los turcos. Los resultados de nuestro estudio mostraron que cuanto menor es el nivel de identidad nacional, mayor es la oportunidad para que los migrantes elijan una estrategia de adaptación marginal. Esta estrategia de comportamiento genera insatisfacción, seguridad social y psicológica del migrante. Habiendo perdido los valores de su cultura, el migrante pierde un estándar adecuado de "imagen del mundo", que subyace en la adaptación del individuo al entorno social. Esto significa que el individuo carece de valores, patrones de comportamiento adecuados, ha perdido el significado de su cultura y, por lo tanto, no puede evaluar y aceptar adecuadamente los valores de la cultura de acogida. La investigación ha demostrado que un alto nivel de indicadores en escalas como la escala de interactividad (19\%) y la escala de adaptación (18\%) indica que los encuestados se sienten lo suficientemente seguros en el nuevo entorno, están abiertos a la cooperación y se centran en sí mismos. -realización, que les da una sensación de seguridad social y física. Esta situación, naturalmente, baja el indicador en la escala de depresión, lo que indica la ausencia de problemas emocionales graves.

Palabras clave: valores, identidad, adaptación efectiva, identidad nacional, cultura. 


\section{Introducción}

Today, Azerbaijan is one of the most successfully developing countries in the world. Political, economic reforms, state programs and major international projects, implemented by our country, have ensured its stable, dynamic and sustainable development. Despite accelerated economic development, there is no shortage of labor and a demographic crisis in the labor market. Nevertheless, the rapid development of our country's economy, expansion of economic, cultural, bilateral and multilateral relations, improvement of quality and living standards, make Azerbaijan very attractive for labor migrants. Every year their number is steadily growing in our country. A lot of labor migrants wish to stay in Azerbaijan. Labor migrants residing in our country as citizens and as without citizenship are already tens of thousands. As representatives of different national cultures, they bring their values to the common value system of our people, on the one hand, and on the other hand, they assimilate the values of our people. This contributes to their adaptation to the new environment, preserving their national identity as an important factor.

It should be noted that Azerbaijan has ratified the UN International Convention on the Protection of Migrants and Their Families, the European Social Charter and has signed several ILO documents. The changes, according to which migrants could enjoy all rights and be provided with them, were added to the national legislation that protects the rights of migrants. The state policy is carried out purposefully and step by step in this direction. A very important and acute issue in solving the problems of migrants is their integration into society. Empirical data show that in some cases integration processes proceed slowly, and sometimes this does not happen at all and various kinds of socio-psychological conflicts are observed with the high tolerance of the Azerbaijani society.

The migrants' national, cultural and religious identity is an essential moment in integrating of migrants into a new ethno-cultural environment and ensuring of consolidation in the society. When interacting with people of a different culture, in a "foreign environment", migrants consciously or unconsciously compare the values of their culture with the values of the representatives of the culture to which they must adapt. Acculturation proceeds favorably and integration is positive when the migrant clearly defines his or her national identity and finds much of the universal, similar in both cultures. To be accepted by representatives of this culture, some migrants try to show in their behavior the values of the culture in which they found themselves. Unconscious, even sometimes not understanding the meaning and therefore inadequate acceptance of the values of another "alien" culture and their displacement with the values of their culture, certainly does not promote adequate self-identification, which sometimes leads to marginalization of the migrant's personality. Thus, a violation of the adequacy of the national self-identification of the migrant leads to collisions not only in social and cultural, but also in the socio-psychological aspect. Migrants who are in a new ethno-cultural environment are 
distinguished by the nature of their national self-identification and experience of their cultural security. Therefore, the development of socio-psychological mechanisms and characteristics of the migrants' values and their impact on the level of their national identity are very important; both in terms of determining the optimal strategy for migrants' acculturation and in terms of developing a flexible state policy in solving the problems of migrants' adaptation in a new ethnocultural environment.

\section{Research hypothesis}

The level of national identity of migrants, in many respects, depends on the orientation towards accepting the values of the culture of the country of residence with the aim of preserving their cultural heritage, which determines the nature of their adaptation in the new environment.

\section{Research Methods}

The methodological basis of the study was made up of the basic methodological principles of scientific psychology, the main provisions of the theory of social psychology, the concept of personality development by Erickson (2016) and the theory of social identity by Tajfel \& Tuner (2004) . The method of "values" by Schwartz (2006), "socio-cultural” test of Yankovsky (1995) and a questionnaire survey were used in the study. To process empirical data, we used statistical methods. The study involved 235 migrants.

\section{Development}

Being used in, both psychology and other social sciences, the concept of value can be characterized as a "characteristic of objects and processes in the world that have a positive or negative value for human life". In sociology, value is understood as accumulated social experience, assimilated by the individual in the course of his socialization.

In cultural science, "value" is understood as a personal meaning for an individual with the help of which the person's attitude to the objective world is manifested (Nekrasova N.A., Nekrasov S.I.,etic.al. 2008) In pedagogy, the problem of values is considered in the context of the upbringing process. It is clear from these definitions, that value can be treated either as an attribute, a characteristic of an object, or as an object itself, which can meet the person's requirements. In the works of psychologists, the definition of the "value" concept is revealed as - something, what a person attributes to a special value in life, what is the bearer of a special and positive everyday content. This definition differs from the term of "value orientations". The definition of "value" is interpreted as an important component of a person's worldview, which expresses his (her) preferences and aspirations (Big psychological dictionary, 2003, p.531).

In his psychoanalytic theory, Z. Freud (2009) points out that the values acquired in the course of socialization play an important role in the substructure of the super-Me, and G. Young -his associate, believes that profound changes of value orientations take place in the refracted stages. For G. Allport, value is the most important part of the individual and, at the same time, he 
distinguishes the following classification of values: aesthetic, theoretical, economic, social, political and religious values.

E. Fromm (1990) believes that there is close contact between values and the emerging character. If some authors consider value as motivating activity, then, according to M.Rokich (2006) they are components of the cognitive structure of the personality that regulates a person's life activity Allport (2008).

E.V. Gavrilova (2012) as well as M.Rokich (1968) considers that in addition to the determination of the cognitive process, values direct and organize behavior for specific purposes, i.e., in her opinion, values regulate people's behavior and contribute to the assessment of the surrounding reality.

In social psychology, values are studied in connection with socialization, dynamic processes in small groups, with a change in the social situation. V.A. Yadov (2013) considers the individual's value orientations as an important stage of the species, as regulating his actions and behavior in situations of special importance, and his social initiative. With the help of these values, the person manifests his attitude to all the circumstances of everyday life. Based on the above definitions and concepts of values, certain conclusions can be drawn . Like society itself, values are a dynamic process and they change more quickly against the backdrop of changes in the socio-economic situation.

The formation of values depends on the individual-psychological characteristics of people, nature of the received education and impact strength of socio-psychological factors. Especially, it is necessary to note the imitation role which influences the formation of value orientations.

The researches of V.M. Kuonsianin show that professional orientation is of particular importance for the formation of values. The study of the system formation of young people's value orientations showed their dependence on the moral and spiritual attributes of society. According to Bandore (2000), the perception process of value orientations is carried out through the stages of modeling and identification, corresponding to the laws of social behavior. He believes that values are formed under the direct influence of the older generation. Approvals and non-preferences on their part contribute to the creation of certain standards.

American scientist Kirshenbaum (2000) indicated 5 stages of this process in the book "Review of development methods of values".

1. Think about values and make decisions.

2. Feelings: to achieve the goal, share your feelings with other people

3. Choice: looking at alternatives and implementing an action plan

4. Communication: listening to others, communicating with them

5. Actions: to achieve the goal of working, persistently influencing behavior (p.182).

There are many weaknesses in this review, of course. For example, can people assess themselves objectively? Psychologists do not have a single answer to this question. Values cannot 
lead to fundamental changes in the inner world of a person, and their explanation cannot be superficial. On the other hand, transformations in a system of value orientations can lead to conflict with surroundings.

Numerous researchers use different methods to study values from the perspective of comparing them between cultures. One of the challenges is the selection of research methods, as the study of intercultural values has a number of characteristics. In this chapter, a number of methods are used to study values in intercultural studies. There are methods that are not directly applied to the study of values in intercultural work, but they are suitable.

To create his own methodology, Cluckhon conducted a lot of theoretical work on determining key values for comparing different cultures. Cross-cultural psychology sets great goals: to understand the differences and similarities between people who come from different cultures. Similarity can be sought at all levels - physiological (our eyes are capable of perceiving color), cognitive (people are able to perceive the relative distance), individual (people can be happy and sad, tender or aggressive), social (all related by kinship with parents, brothers and sisters), cultural (we accept the cultural norms of our own cultural heritage) (Kluckhohn \& Strodtbeck, 1961).

These cultural norms can accept a variety of patterns. They can be very specific, such as an acceptable type of clothing or very complex and abstract, like our religious beliefs. One of the important types of norms is the prevailing attitude towards other people and objects. These relationships are already being studied by social psychologists. In the 20-30s of the 20th century, it was believed that if accurately measured, they would predict a person's behavior. However, the relationship is much more a complex than psychologists assumed and therefore they began to look for a more fundamental concept that could predict behavior. Values were assigned to these concepts. Rokich (1968) suggests that people have more than 36 values; Herskovits (1945) believes that their number can be limited to five times.

The concepts such as honesty and courage, peace and wisdom are recognized in all human cultures. Nevertheless, from 1931 to the present time, there are basic human values that are investigated by the psychologists. They are measurable and an exciting topic for the study. The disclosure of these values and invention of their measuring means have facilitated understanding similarities and differences between people.

One of such theories, studying the basic human values, is the theory of Cluckhon and Strodtbeck (1961). Cluckhon argued that people differed from each other by their biological features and characteristics that formed the foundation for the development of culture. He defined the value as: "this is the concept of the desired, external and explicit or hidden-internal, purely individual or characteristics of the group that influences the choice from the available means, means and ultimate goals of action." (Kluckhohn \& Strodtbeck, 1961).

Cluckhon \& Strodtbeck (1961) developed a theory consisting of three fundamental assumptions: 
1. There are a limited number of common human problems, for the solution of which the peoples should find some way out in any case.

2. Due to the fact that there are different ways of solving all problems (they are not endless and random) is a particular variable that accepts a limited number of values.

3. All alternatives to all decisions are present in all societies in any case, but are differentiated by people (p.170)

They suggested that solutions to these problems, preferred by this society, constitute the values of this society. Therefore, the measurement of preferred solutions indicates the values supported by a particular society.

\section{Discussion}

The research showed that the most significant for the entire sample of respondents is the value of security, and the least significant - the tradition. These figures are somewhat different when it comes to men and women. So, for example, if the value of "safety" (5.2) for women is of the first importance, and independence of the second (4.69), then for men, hedonism is first (4.79), and the second is security $(4,64)$. Traditions $(3.57)$ are the least important for women; while the last place was divided by stimulation (3.75) and tradition (3.76) for men ( Table 3.1).

Table 1.Average indicators of the significance of value types

Average indicators of the significance of value types

\begin{tabular}{lccc} 
Value types & For all & male & female \\
\hline Conformity & 4,29 & 4,20 & 4,46 \\
\hline Traditions & 3,70 & 3,76 & 3,57 \\
\hline Kindness & 4,21 & 4,04 & 4,21 \\
\hline Universalism & 3,92 & 3,88 & 3,99 \\
\hline Self-dependence & 4,58 & 4,53 & 4,69 \\
\hline Stimulation & 3,89 & 3,75 & 4,18 \\
\hline Hedonism & 4,48 & 4,79 & 3,82 \\
\hline Achievements & 4,16 & 4,13 & 4,21 \\
\hline Power & 4,02 & 4,16 & 3,73 \\
\hline Security & 4,82 & 4,64 & 5,20
\end{tabular}

These results allow us to draw some conclusions. Thus, the respondents' choice of the "security" value shows the migrant's aspirations to the social order in the surrounding him reality regardless of gender; as well as opportunities to freely discover their national-ethnic identity, individual or personal security, family safety and health. However, there are some differences in 
the choice between men and women. Preferring independence, women demonstrate their need for autonomy and creativity. It can be assumed, that having retained some autonomy, exactly the creative approach to reality and certain flexibility allow smoothing out and facilitating women's adaption to the new environment. Unlike women, men prefer hedonism, that is, they idealize sensual pleasure and enjoy life, thus seeking to compensate for the lack of stability in social relations. When analyzing the data, the result for the least significant value was very important for us. In our sample these were traditions reflecting customs, rituals and ideas, ethnic and other stereotypes of behavior that exist in culture. This accentuates the problem associated with the motivating role of ethnic identity in the process of migrant entry into a new ethno-cultural environment. When entering a new ethno-cultural environment, migrants face a process of double expectation which manifests itself in how it would be a new group, and how it would adopt a new group. Naturally, in this process, ethnic stereotypes and ethnocentrism play an important regulatory role of behavior in an unfamiliar situation.

At the next stage of data processing, ranking of values was carried out according to the degree of their importance. In accordance with the average score for each type of values, their rank ratio is established (Table 3.2). Each type of values gets a significance from 1 to 10 . The value with the highest average score is worth the first position and the lowest average score is on the tenth level. Values on positions 1 to 3 are of great importance for the test. The position from 7 to 10 is not an indicator of high significance to these values.

Table 2. Rank values of types of values at the level of normative ideal

Rank meanings of value types

Types of values

\begin{tabular}{lccc} 
& For all & men & women \\
Conformity & 4 & 4 & 3 \\
\hline Traditions & 10 & 9 & 10 \\
\hline Kindness & 5 & 7 & 5 \\
\hline Universalism & 7 & 8 & 2 \\
\hline Self-dependence & 2 & 3 & 6 \\
\hline Stimulation & 8 & 10 & 8 \\
\hline Hedonism & 3 & 1 & 9 \\
\hline Achievements & 6 & 6 & 1 \\
\hline Power & 7 & 5 & 4 \\
\hline Safety & 1 & 2 & 9
\end{tabular}


To analyze the results, we used a theoretical model of the relationship between the ten motivational types of Schwartz values, which include, as noted above, two bipolar axes of measurement. In our study, migrants demonstrated ambivalence on the "openness-conservatism" scale, that is, the desire for stability and order, on the one hand, and the desire to change and adapt to the other. On the scale of "self-elevation - self-transcendence" the results unambiguously show the importance of such values as universalism and kindness, that is, the model gravitates toward the pole of "self-elevation".The study showed that in the situation of migration, the person in his behavior most of all attaches to achieving social status or prestige, focusing on social respect and maintaining his public image. At the level of individual priorities, "security" is also important. Interesting is the fact that choosing hedonism as an ideal value, men in real behavior put it on one of the last places. Reality, everyday, economic problems, struggle for survival, the need to adapt make the desire for pleasure less important for a person in a new socio-cultural environment. The fact that the "prosocial" type of values "kindness", which provides well-being in everyday interaction with close people, is also activated on the vertex level, and manifests itself in loyalty, condescension, honesty, is responsible for the greater role of adaptation mechanisms for the migrant.

Table 3. The average indicatorsconcept of the of the importance of types of values at the level of individual priorities

\begin{tabular}{|c|c|c|c|}
\hline \multirow{2}{*}{ Types of values } & \multicolumn{3}{|c|}{ Average indicators of the significance of value types } \\
\hline & For all & & women \\
\hline Conformity & 3,74 & 3,50 & 4,23 \\
\hline Traditions & 3,79 & 3,57 & 4,23 \\
\hline Kindness & 4,38 & 4,32 & 4,50 \\
\hline Universalism & 3,93 & 3,83 & 4,15 \\
\hline Self-independence & 4,24 & 3,98 & 4,79 \\
\hline Stimulation & 4,47 & 4,51 & 4,38 \\
\hline Hedonism & 3,89 & 3,67 & 4,36 \\
\hline Achievements & 4,38 & 4,48 & 4,17 \\
\hline Power & 4,58 & 4,51 & 4,74 \\
\hline Safety & 4,50 & 4,45 & 4,58 \\
\hline
\end{tabular}


Table 4. Rank meanings of value types at the level of individual

priorities

\begin{tabular}{l|l|l|l}
\multirow{2}{*}{ Value types } & \multicolumn{2}{c}{ Rank meanings of value types } \\
\cline { 2 - 4 } & For all & men & women \\
\hline Conformity & 10 & 10 & 8 \\
\hline Traditions & 9 & 9 & 7 \\
\hline Kindness & 5 & 5 & 4 \\
\hline Universalism & 7 & 7 & 10 \\
\hline Self-independence & 6 & 6 & 1 \\
\hline Stimulation & 3 & 2 & 5 \\
\hline Hedonism & 8 & 8 & 6 \\
\hline Achievements & 4 & 3 & 9 \\
\hline Power & 1 & 1 & 2 \\
\hline Safety & 2 & 4 & 3 \\
\hline
\end{tabular}

As can be seen from Tables 3 and 4, at the level of personal benefits (that is, in real actions), values such as power, security, and stimulation are at the maximum level. The least important, at the level of normative ideals have traditions and stimulation, and at the level of individual priorities have values such as conformance and tradition (Pictures 3.3 and 3.4).

The main problem faced by every person who has been in a new cultural environment for him is to understand and accept it. For migrants, this task consists in choosing between identity modification and assimilation their identity and isolating themselves. Naturally, for a country that accepts a migrant it is desirable that migrants successfully adapt and can be fully realized. Considering this, we were tasked to investigate the peculiarities of adaptation of migrants and the influence of their identity on this process. To solve the problem on the basis of the analysis of the method for studying the features of adaptation, we selected the method of LV Yankovsky (2004), since this methodology has scales that include elements inherent in the identity structure. Methods of "Adapting an individual to a new socio-cultural environment" by LV Yankovsky are testing as a process of quantitative measurement of individual- psychological differences, responding to the requirements of representativeness, reliability, validity, and reliability.

Interpretation of data is carried out on the basis of using two criteria: in qualitative comparison with the norm or standard, which may be representations of non-pathological development or socio-psycho-logical norms, with a subsequent conclusion about the presence or absence of a certain attribute; in a quantitative comparison with the group, with the subsequent conclusion 
about the ordinal position among others. The questionnaire includes 6 scales corresponding to different types of adaptation. Scales: adaptation type - adaptive, conformal, interactive, depressive, nostalgic, alienated.

I want to note that there is an internal relationship between the two methods of research. Despite the fact that the purpose of this scientific work res87was not to study this relationship, but in the structure of the social behavior of the individual there are relations of the motivational values of the migrant to this new subculture. In the process of adaptation to a new subculture, such values as social order, family safety, solidarity, mutual assistance, a sense of belonging acceptance of custom and ideas is meaningful. According to Yankovsky's methodology, the scale of adaptability and conformity formulates in the personality such values as conformity, and in the scale of interactivity, as a value of independence.

An experimental sample plays an important role in testing experimental hypotheses. In many respects it determines the success of the work of statistical hypotheses.

Considering this in the article, the following apparatus analysis was used to form a sample and check statistical hypotheses $(\mathrm{H})$.

Yankovsky's method for these purposes uses for sampling the notion of a sample sum, which for a mathematical sample (a0, a1, a2, a3) is treated as a random variable:

$$
a_{i}=\sum_{j=0}^{96} x_{j}, \quad i=0,1,2,3 \quad(1)
$$

Here $x_{j}=1$, if the evaluation of the $j$-th question is a sampling. 96-number of questions.

First you have to determine the significance of the criteria. Significance test at significance level $\alpha(0<\alpha<1)$ uniquely determines rule, establishing conditions under which checked statistical hypothesis $\mathrm{H}$ should be rejected, or taken on the basis of a specific sample (a0, a1, a2, a3). At the same time build a proper sample characteristics hypothesis $t$, which is a function of the results of observations. In addition, the critical region $\mathrm{K}$ is set depending on $\alpha$ as follows: assuming validity of the hypothesis $\mathrm{H}$ probability that a characteristic value owned by the critical region $\mathrm{K}$ is equal, at most, $\alpha$. In the exercise of hypothesis testing procedures, initially as a result of the particular sample, calculate the sample characteristic t. If the calculated value of the characteristics falls on the critical region $\mathrm{K}$, then the hypothesis $\mathrm{H}$ is rejected. Otherwise, i.e. if the value of $\mathrm{t}$ misses the critical region $\mathrm{K}$, the hypothesis $\mathrm{H}$ is not objectionable and sample data characterize it as possible and very plausible.

To test the statistical hypothesis about representative sample study used the Cochran test. The hypothesis was tested separately for male and for female. According to the results of the procedure to determine the degree of success of adaptation to the new environment socio-cultural, for 4 different samples was first calculated sample variance and mean value of the xi sample relevant to the following formulas:

$$
s_{i}^{2}=\frac{1}{m-1} \sum_{j=1}^{m}\left(x_{i j}-\bar{x}_{i}\right)^{2} \quad \text { (2) } \quad \bar{x}_{i}=\frac{1}{m} \sum_{j=1}^{m} x_{i j}(3)
$$


Here $i=0,1,2,3 ; m=96$. the characteristic parameters were calculated for each sample separately for male and female:

Table 5. Evaluation table of mean and sample variances for a male's single sample

\begin{tabular}{l|l|l|l|l}
\hline & \multicolumn{1}{|c|}{$a_{0}$} & \multicolumn{1}{|c|}{$a_{1}$} & $a_{2}$ & $a_{3}$ \\
& & & & \\
\hline $\bar{x}_{i}$ & 0,62963 & 51,7037 & 37,8519 & 5,81481 \\
\hline$s_{i}^{2}$ & 1,86772 & 86,8439 & 84,336 & 86,4312 \\
\hline
\end{tabular}

Results presented in the table can also be shown by the graph. This graph shows the evaluation results of average values for men.

Table 6. Evaluation mean and the sample variance of a single sample for female

\begin{tabular}{l|l|l|l|l}
\hline & $a_{0}$ & \multicolumn{1}{|c|}{$a_{1}$} & \multicolumn{1}{c}{$a_{2}$} & $a_{3}$ \\
& & & & \\
\hline $\bar{x}_{i}$ & 0,307692 & 51,76923 & 41 & 2,923077 \\
\hline$s_{i}^{2}$ & 0,197802 & 83,02198 & 52,57143 & 49,92308 \\
\hline
\end{tabular}

Cochran criterion is used to test the hypothesis of equality of variances $\mathrm{H}$ dispersions. The criterion is based on statistics $k \geq 2 \mathrm{~s}_{-} \mathrm{i}^{\wedge} 2$

$$
t=\max _{i=0,1,2,3} \frac{s_{i}^{2}}{\sum_{j=1}^{k} s_{j}^{2}}(4)
$$

Based on the asymptotic distribution statistics (4) the critical values calculated for the different levels of significance $\alpha$ [1]. $m 1, m 2 ; \alpha \mathrm{C}$ Hypothesis testing rule: hypothesis $\mathrm{H}$ is rejected if $m 1, m 2 ; \alpha t>\mathrm{C}$ the number of sampling workers. Critical values found from the table [1]. $m 1=k m 2 m 1, m 2 ; \alpha \mathrm{C}$ When, and $\alpha=0,01$ for sample men find critical. According to Table 3.1 the maximum variance estimation.

To test the hypothesis $H$ at significance level $\alpha=0,01$ calculate statistical significance $m 1=4 m 2=76 \mathrm{C} 4 ; 76 ; 0,01=0,4057 s_{1}^{2}=86,8439$

$t=\max _{i=0,1,2,3} \frac{s_{i}^{2}}{\sum_{j=1}^{k} s_{j}^{2}}=\frac{86,8439}{1,86772+86,8439+84,336+86,4312} \approx 0,334686$

Since, $\mathrm{t}<0.4057$, the results of the observations are assumed not to contradict the hypothesis $\mathrm{H}$. Now, for the female at $\mathrm{m} 1=4, \mathrm{~m} 2=24$ and $\alpha=0.01$, we find the critical value $\mathrm{C} 4.24,0.01=0.4884$. The maximum variance estimates are $\mathrm{s} 12=83.02198$. To test the hypothesis $\mathrm{H}$ at the significance level $\alpha=0,01$, calculate the value of the statistics 
$\mathrm{t}=\operatorname{maxi}=0,1,2,3 \mathrm{si} 2 \mathrm{j}=1 \mathrm{ksj} 2=83,021980,197802+52,57143+83,02198+49,92308 \approx 0,447$

(6) . Since $t<0.4057$, the results of observations for the female sex are also considered not to contradict the hypothesis of $\mathrm{H}$.

These calculations confirm that we have enough information, and statistical calculations can be continued to analyze the main hypothesis about the features of migrant adaptation to a new socio-cultural environment. Our work allows us to make some generalizations that will help to better understand the problems of migrants. As the study showed, subjects, in which values of the national culture were not significant in the hierarchy of values, demonstrated a good adaptation to the new ethno-cultural environment. The model described above works here, with an emphasis on the value of the host. Of course, for the entry into a new culture, the values of security and autonomy, which in our study were significant for both Koreans and Turks, are important. A person from birth assimilates the rules and norms defined by the cultural environment, which later regulate his behavior. Values, attitudes, social norms have an adaptive function. They allow the individual to successfully exist in their culture and generate a sense of belonging and involvement with it.

\section{Conclusions}

Our research has shown that the study of gender and age characteristics of forced migration, as well as the study of the socio-psychological basis of changes in values in the adaptation process, allows us to better understand the mechanism of migration processes and find new solutions to migrant adaptation problems allows you to help.

Our research was conducted by Yankovsky, (2004), Gavrilova, (2016), Yadov, (2013) and others. Although it overlaps with other studies, it contradicts a number of studies. Rudnev (2014) opposes the general assumption that basic human values remain constant throughout an individual's life. It shows that the values of migrants are more likely to change after moving to a new country. Surprisingly, the value of migrants in relation to the country of residence seemed to be higher than in the country of birth. In addition, the values of migrants are more in line with the values prevalent in the country of residence than the values prevalent in the country of birth. Considering that migrants' value-based choices are insignificant, the results support the idea that core values can change not only in the formative years, but also throughout an individual's life (Rudnev, 2014).

A number of studies have shown that language skills and cultural compatibility play an important role in the adaptation of migrants (Gurieva, S., Kõiv K., etic.al, 2020). Studies by Marie \& Vincent (2014) show that the migration process also depends on the mental health of migrants and the responsible approach of health workers to this process. Migration has an impact on all spheres of human life, changing the usual course of events, causing a certain transformation in the structure of values. Today we have four models of entering a new ethnocultural environment 
and, accordingly, four models of value transformation as the basis of ethnic identity. The migrant can isolate himself from the new cultural environment, giving preference to the values of his people, negatively evaluating everything new that does not fit into the usual pattern of behavior. The mechanism of in-group favoritism will work here, prompting people to choose representatives of their ethnic group for communication. The migrant can see his safety in full acceptance of the new culture, its values and stereotypes of behavior. At the same time, there is a negative, critical attitude towards their culture. A more flexible option is to take the best of the new culture and preserve your ethnic identity. There are also cases of a kind of ethnic nihilism, rejection of the values of both one's own and another's culture.

\section{References}

Malone J.C., Liu S.R, Vaillant G.E. etic.al (2016). Midlife Eriksonian psychosocial development:Setting the stage for late-life cognitive and emotional health. Dev.Psychol. 2016;52(3):496-508. doi:10.1037/a0039875

Tajfel, H., \& Turner, J. C. (2004). The Social Identity Theory of Intergroup Behavior .Political psychology: Key readings (p.276-293). Psychology Press. https://doi.org/10.4324/9780203505984-16

Yankovsky, L. V. (2004). Questionnaire for adapting the personality to a new socio-cultural environment. SPb.,, p. 190-194.

Nekrasova, N.A., Nekrasov S.I.etic.al (2008). Philosophical dictionary subject.Moscov;164 p.

Big psychological dictionary (2003). Ed. Meshcheryakova B.G., Zinchenko V.P. M : PrimeEvroznak, 672 p. p. 537

Freud, Z. (2009).Beyond the Pleasure Principle.. Psychology of the masses and analysis of the human "I" - Kharkov: Folio.

Allport, G.V. (1998). Personality in psychology. Per. from English. M .: SPb., 345 p.

Fromm, E. (1990). Man for himself: An inquiry into the psychology of ethics. New York: Henry Holt and Company.Google Scholar

Gavrilova, T.M. (2016). Factors contributing to population migration. www.volsu.ru/RES_C/VGI/ .../5.../gavr lovaru-factory.pdf

Rokeach, M. A (1968). Theory of Organization and Change Within Value-Attitude Systems. J. Soc. Iss. 24, 13-33. [CrossRef]

Yadov, V. A. (2013). Self-regulation and forecasting of social behavior of a person: a dispositional concept. 2nd extended ed. - M .: TsSPiM. 
Bandura, A. (2000). Social learning theory. Saint Petersburg: Eurasia, 320 p., H. (2000). From Values Clarification to Character Education: A Personal Journey.The Journal of humanistic education and development 39(1)DOI:10.1002/j.2164-490X.2000.tb00088.x

Kluckhohn F.R., Strodtbeck F.L. (1961)/ Variations in Value Orientations. IL, p. 170.168

Herskovits M. The Processes of cultural change. The Science of man in the world crisis/ Ed. by Linton R. New York, 1945, p. 143-170.

Kluckhohn F.R., Strodtbeck F.L.(1961). Variations in Value Orientations. IL 1961, p. 170.168

Rudnev, M. (2014). Value Adaptation Among Intra-European Migrants: Role of Country of Birth and Country of Residence. Research Article. https://doi.org/10.1177/0022022114548482

Gurieva, S., i Kõiv K., and etic. (2020). Al. Migration and Adaptation as Indicators of Social Mobility Migrants. Behav. Sci. 2020, 10, 30; doi:10.3390/bs10010030

Marie, D. and Vincent L. (2014). Adaptation of health care for migrants: whose responsibility? Health Services Research 2014, 14:294 http://www.biomedcentral.com/1472-6963/14/294 